\title{
Seismic and Aseismic Slip on the San Andreas Fault ${ }^{1}$
}

\author{
C. H. Scholz, ${ }^{2}$ M. Wyss, and S. W. Sмith \\ Seismological Laboratory, California Institute of Technology, Pasadena, California 91105
}

\begin{abstract}
Field and experimental evidence are combined to deduce the mechanism of slip on shallow continental transcurrent faults, such as the San Andreas in California. Several lines of evidence portray the central section of the San Andreas fault as a very smooth and flat surface, with a very low frictional strength in comparison to the breaking strength of intact rock. The Parkfield earthquake of June 27, 1966, and its aftershock and creep sequences are examined as a detailed example of fault slippage that includes both types, seismic and aseismic. It is shown from considerable number of field data that during the main shock a region from about 4 to $10 \mathrm{~km}$ in depth slipped approximately $30 \mathrm{~cm}$. In response to this slippage, creep and aftershocks were generated. The creep and aftershocks are not directly interrelated, but they are microscopically identical processes of time-dependent brittle friction occurring in parallel in different regions. The creep occurred by time-dependent stable frictional sliding in the 4-km-thick surface layer; the aftershocks, by time-dependent stick-slip at the ends of the initial slipped zone. This model is in good agreement with laboratory results which show that slippage should occur by stable (aseismic) friction in the upper $4 \mathrm{~km}$, by stick-slip accompanied by earthquakes from about 4 to $12 \mathrm{~km}$, and by stable sliding or plastic friction below $12 \mathrm{~km}$ on the fault. One feature not observed in the laboratory is the episodic nature of creep. These episodes can be predicted with an accuracy of about 1 week.
\end{abstract}

\section{INTRODUCTION}

It is by now well known that slip on a fault can take place in at least two uniquely different ways. In some situations, slip may occur at a rate comparable to the elastic-wave velocity of the surrounding rock. Such slip is efficient in exciting seismic waves and results in an earthquake. In other situations slip may occur at a comparatively slow rate and consequently does not generate an earthquake. Both modes of slip, seismic and aseismic, are accommodation of the crust to tectonic stresses and have the same effect in relieving such stresses. Therefore, since there is more than one way to relieve tectonic stress, only one of which is a hazard to man, the ultimate solutions to the problems of earthquake prediction, of estimating earthquake risk, and perhaps eventually of even preventing earthquakes must turn on an under-

${ }^{1}$ Contribution 1564, Division of Geological Sciences, California Institute of Technology, Pasadena, California.

2 Now at Lamont Geological Observatory of Columbia University, Palisades, New York 10964.

Copyright (C) 1969 by the American Geophysical Union. standing of the conditions by which slip on faults is released seismically or aseismically.

To approach this problem, we must first understand the physical processes operating when slip occurs on a fault. This study is a first attempt in that direction. We begin by combining field evidence with the considerable amount of recent experimental work on the earthquake mechanism to describe some general features of slippage on faults such as the San Andreas in California. Then, using the 1966 Parkfield, California, earthquakes as our point d'appui, we test these concepts in detail.

\section{Role of Friction}

The problems with which we are primarily concerned are the mechanism of fault creep, which is slow slip of the fault and purportedly aseismic, and of earthquakes. To proceed, we shall discuss the role frictional processes play in sliding on faults such as the San Andreas.

State of stress. The fact that large shallow earthquakes in regions such as California occur repeatedly on discrete and very well-defined planes [see, e.g. Allen et al. 1965] clearly demonstrates that they are a frictional sliding phenomenon. Nevertheless, it has been argued [viz. Orowan, 1960] that any normal form of fric- 
tional sliding would require stresses much higher than are indicated by observed stress drops. The coefficient of friction on rock surfaces normally ranges from about 0.4 to 1.8 [Jaeger, 1959; Handin and Stearns, 1964], which suggests that the stress necessary to cause frictional sliding on a fault is at least an order of magnitude higher than stress drops derived from seismic observations [Brune and Allen, 1967b]. Brace and Byerlee [1966] suggested that stick-slip frictional sliding was the mechanism of earthquakes and, in the light of the above difficulty, maintained that the stress drop need be only a small fraction of the total stress. It is the intent of this paper to combine the field data as closely as possible with laboratory results in an attempt to understand the mechanisms of earthquakes and fault creep. These processes will be examined in the light of the stick-slip hypothesis. Consequently, before beginning our analysis we must attempt to reconcile the major dilemma of the strength of the fault. Is the stress on the fault much higher than the stress drop during an earthquake, or is there some way by which the frictional strength can be lowered substantially from that normally observed in laboratory experiments?

The stress required to produce an earthquake has not been determined by direct means. The pertinent available information is the stress drop and the product of seismic efficiency and average stress before and after the shock. The results of King and Knopoff [1968], however, suggest a method for relating the stress drop during an earthquake to the initial stress. Suppose that, following Tsuboi [1956], we assume that the strain energy density required to produce an earthquake in a given seismic region is constant, regardless of the size of the earthquake. This is equivalent to the hypothesis that the stress required to initiate an earthquake is independent of the size to which that earthquake grows. This assumption is justified by the broad size spectra of earthquakes occurring in a limited region, as has been emphasized by many studies of the frequency-magnitude relation. With this assumption, the approximate total stress in a region can be determined from the stress drops associated with earthquakes by using the fractional stress drop model of King and Knopoff. In Figure 1 the stress drops of earthquakes that occurred on the San Andreas fault are plotted as a function of magnitude. Fitted to the data is King and Knopoff's relation. With the assumption that the maximum possible earthquake is one of magni-

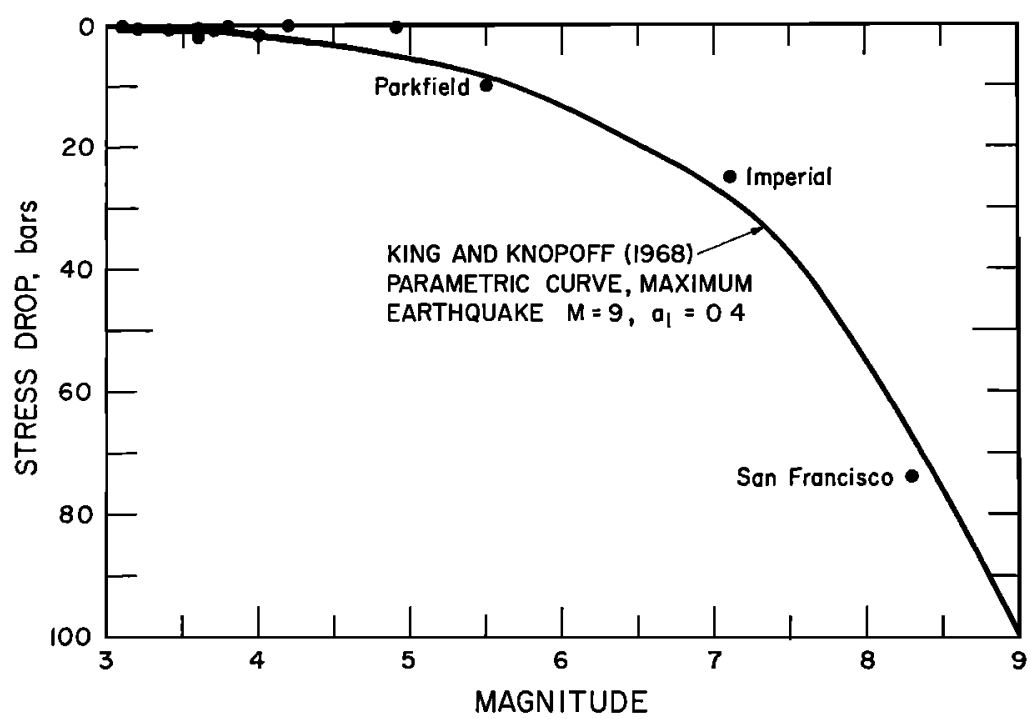

Fig. 1. The stress drops of San Andreas earthquakes plotted versus their magnitudes. The parametric curve of King and Knopoff is fitted to the data to determine the total stress. Data is from San Francisco 1906 and Imperial 1940 and 1966 [Brune and Allen 1967b]; Parkfield $1966[A k i, 1968 a]$; and smaller earthquakes [W yss and Brune, 1968]. 
tude 9 , a very good fit to the data is obtained with the parameters $a_{1}=0.4$ and a total stress of 100 bars.

The most sensitive parameter in fitting the data in Figure 1 is the total stress, which determines the scale of the ordinate. Other parameters that come into the relation, such as the seismic efficiency, are less well defined. The parameter $a_{1}$ suggests a value of about 0.1 for the efficiency, which is close to the value observed in model experiments by Vasil'yev [1968]. Wyss and Brune [1968] determined the product of seismic efficiency and average stress from the moment-magnitude relation of small earthquakes at Parkfield. They obtained a value of approximately 10 bars. As a test of consistency, we can apply the above value of efficiency to this, which again indicates an initial stress of around 100 bars, since the stress drops of those small earthquakes were only of the order of a bar. Whereas the stress determined in this way may not appear on first examination to be reliable, it is encouraging that this value lies between the minimum value of 74 bars, given by the stress drop of the 1906 San Francisco earthquake [Brune and Allen, $1967 \mathrm{~b}]$, and the maximum value of around 200 bars, determined by the absence of a heat flow anomaly on the San Andreas fault [Brune et al., 1968]. Consequently, we feel confident that the value of 100 bars is a fairly good estimate of the stress on the straight portions of the fault.

Frictional strength. Byerlee $[1967 a, b]$ has extensively studied the frictional strength of rock and has found that the shear stress required to initiate sliding is generally in the form

$$
\tau=\tau_{0}+\mu p
$$

where $\tau$ is the shear stress, $p$ is the normal stress on the surface, and $\tau_{0}$ and $\mu$ are constants. The $\tau_{0}$ term is probably due to the effect of interlocking. He determined values of $\tau_{0}$ and $\mu$ of $0.5 \mathrm{~kb}$ and 0.6 , respectively, for westerly granite under high confining pressure. His experiments at low normal stress yield a better measure of $\tau_{0}$, however, and show that the value is closer to 30 bars.

One of his most interesting conclusions was that the coefficient of friction of brittle materials is a function of surface roughness. $\mathrm{He}$ found that the coefficient of friction of westerly

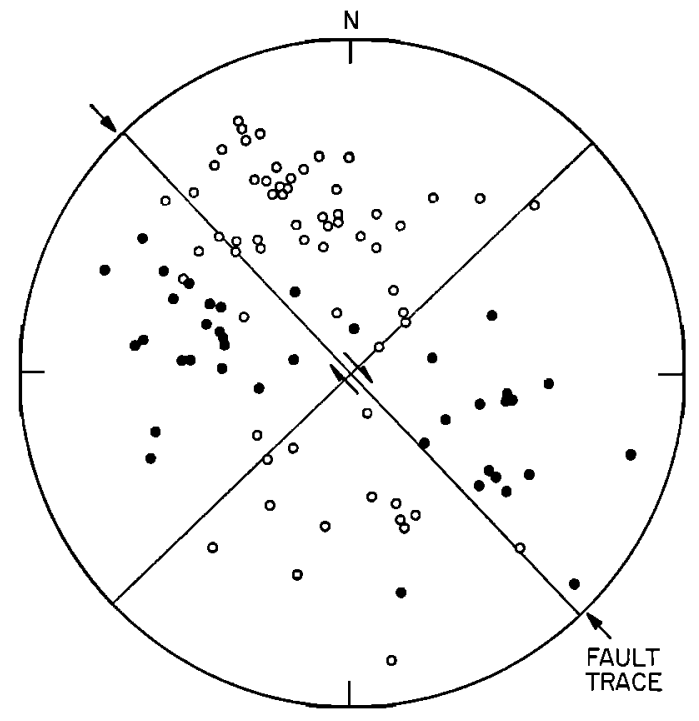

Fig. 2. Composite fault plane solution (lower hemisphere) of twenty-two microearthquakes located near Parkfield, California, from October 1 to November 15, 1967. Open circles, dilatations; closed circles, compressions. Mapped fault trace is indicated by arrows.

granite decreased from 0.6 to 0.2 as the CLA roughness decreased from 300 to 20 microinches [Byerlee, 1967b]. For ideally smooth surfaces, he argues that the coefficient of friction may be as low as 0.1 . This is of interest because there is reason to believe that the San Andreas fault is a very smooth surface, and accordingly it may have a very low frictional strength. From October 1 to November 15, 1967, a six-station microearthquake array was operated by the Seismological Laboratory in an area of the San Andreas fault near Parkfield, California. In Figure 2 we show a composite fault plane solution for twenty-two of the shocks detected during that study for which satisfactory depths were obtained. The locations of the shocks are given in a later section. Figure 2, a lower-hemisphere projection, was obtained by superimposing individual solutions for each of the shocks. The data were from first arrivals at the six local stations, except for two larger shocks, which were also recorded on the southern California network. None of the shocks were recorded at sufficient stations to yield an individual mechanism solution, but with the composite method the source parameters that the 
shocks have in common can be obtained. In this case the data strongly delineate two nodal planes, indicating that all the earthquakes used in the solution had nearly identical mechanisms. The solution indicates right-lateral movement on a vertical fault, with one of the nodal planes within a few degrees of the average trace of the San Andreas fault in the area.

The magnitude of the earthquakes used in the mechanism study ranged from 3.4 to as low as about 1, with most of the shocks lying in the approximate range of magnitude 1 to 2 . Therefore the shocks sampled portions of the fault ranging from tens of meters to kilometers in length if any reasonable relation between size and magnitude, such as that of Tocher [1960a], is assumed. Together with Eaton's [1968] evidence that all aftershocks of the ParkfieldCholame earthquake sequence occurred directly on the fault, within the accuracy of his measurements $(0.5 \mathrm{~km})$, the present evidence for the identical mechanism of microearthquakes over a substantial length of the fault indicates that the San Andreas fault in this area is an extremely smooth and flat surface over a considerable dimensional range. Byerlee reports a value of $\tau_{0}$ of about 30 bars for smooth surfaces measured in the laboratory. He has also shown that this value may be reduced if water is present. The slow strain rates involved and the presence of gouge in the fault zone will also tend to reduce the degree of interlocking. Accordingly, $\tau_{0}$ is probably quite small, and we can ignore this parameter for the purposes of estimating the average frictional strength of the fault and use the relation

$$
\tau=\mu p
$$

where $\mu$ is the coefficient of friction.

The coefficient of friction of a brittle material such as rock is very dependent on the roughness of the surface. This is largely an effect of interlocking. The above observation that the San Andreas fault is very smooth indicates that it may have a very low coefficient of friction. Byerlee [1967b] has postulated a model for brittle friction on smooth surfaces. His results show that the coefficient of friction on such surfaces should be independent of the strength of the materials in contact but will depend on the average apical angle of the asperities. Let us assume that the fault corresponds to such an ideally smooth surface. The semiapical angle can be estimated from the microearthquake focal mechanism data. An average asperity on the fault, as schematically represented in Figure 3 , probably has a wavelength of the order of kilometers. The nodal planes of mechanisms of microearthquakes that have fault lengths of only tens or hundreds of meters will map out the surface of the asperities. Consequently, the angular uncertainty in determining nodal planes from a composite fault plane solution for a large number of microearthquakes distributed over a long length of fault, due to variation among individual fault planes, will be equal to the angle $\beta$ shown in Figure 3. This angle is twice the complement of the semiapical angle $\alpha$ of the average shaped asperity. The data given in Figure 2 indicate that the angle $\beta$ is less than $10^{\circ}$ in the Parkfield region. From Byerlee's [1967b] model of friction with wedge shaped asperities, the coefficient of friction for this region with asperities of semiapical angle $85^{\circ}$ is 0.075 . This value is probably an upper estimate; his cone-shaped asperity model indicates that $\mu$ is vanishingly small at $\alpha>75^{\circ}$. Even if the asperities are randomly shaped, $\mu$ would only be about 0.15 . The average frictional strength of the fault over a depth of 0 to $15 \mathrm{~km}$, from the calculated value of $\mu$ and equation 2 , is 150 bars. In this calculation we have assumed that the normal stress on the fault is equal to the overburden pressure. This is again probably an overestimate, for if the crust is elastic the horizontal stress in the absence of a normal component of tectonic stress

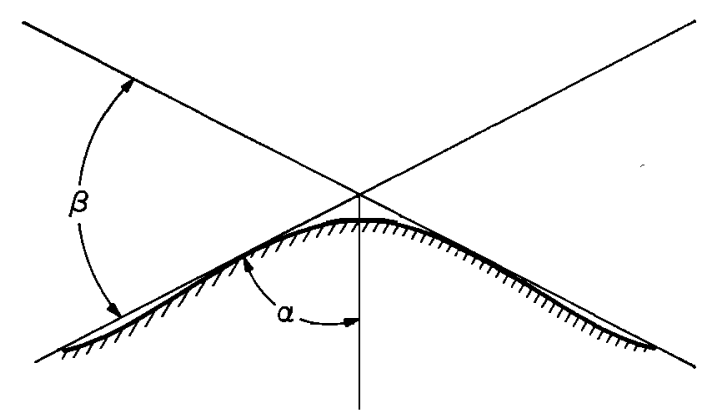

Fig. 3. A schematic representation of an average shaped asperity on the fault is indicated by the shaded curve. The angular configuration of the asperity as described by the parameter $\beta$ can be determined from microearthquake focal mechanisms as described in the text. 
would be less than the overburden pressure by a factor of $v /(1-v)$, where $v$ is Poisson's ratio. That this may be the case has been demonstrated by borehole stress measurements in deep mines in South Africa [Leeman, 1964].

In view of the uncertainty in the calculations, this strength value, $150 \mathrm{bars}$, is indistinguishable from the value of 100 bars estimated for the stress required to produce an earthquake. In conclusion, therefore, these results show that the tectonic stress on the San Andreas fault is indeed sufficient to produce faulting by brittle friction, provided that the fault is very smooth and friction is brittle, as proposed by Byerlee. Consequently, we can tentatively accept the stick-slip hypothesis of Brace and Byerlee and discuss sliding on the fault in the light of laboratory studies of frictional sliding. According to these calculations, the fault is an extremely weak low-friction surface, with a strength far less than that of the surrounding rock. This by itself can explain the very high concentration of seismic activity along this narrow zone.

It should also be pointed out that the values of stress and strength calculated above are only applicable to limited lengths of the straight portions of the San Andreas fault. Our estimates of smoothness of the fault are only applicable to lengths of the order of a kilometer or longer in a $40-\mathrm{km}$-long zone near Parkfield. Since our estimates of stress are also based on data from straight parts of the fault, the comparison of the two calculations is probably valid. On the other hand, the strength of the San Andreas as a whole, taking into account the curved portion of the fault from Cholame south to Big Bear Lake, may be considerably larger. Variations of frictional strength may be responsible for the variety of patterns of seismicity observed along the fault by Allen et al. [1965], and Allen [1968].

Stick-slip and stable sliding. Frictional sliding of rock is sometimes punctuated by jerky motion, i.e. stick-slip. Rapid stress drops produced by stick-slip motion on faults has been suggested as the mechanism of earthquakes [Brace and Byerlee, 1966]. Not all the displacement during frictional sliding is manifested in stick-slip events, however. Except possibly in the special case of totally interlocked surfaces, stick-slip is preceded and followed by variable amounts of stable sliding, i.e. sliding unaccompanied by measurable stress drops. That stable sliding is also a brittle process is clear; laboratory experiments indicate that it is accompanied by microfracturing [Scholz, 1968a]. Both processes are due to brittle fracture of asperities. The type of sliding that will occur seems to depend on the presence or absence of an instability required in order for the fractures to grow to a macroscopic size. Brace and Byerlee [1966] suggested that this instability is due to a variation of frictional resistance with displacement. Although stable sliding is accompanied by small-scale fracturing, it is likely that most of this activity is usually below the dynamic range of any microearthquake apparatus now in operation. Therefore fault slippage will, in general, be partly due to motion during earthquakes and partly due to aseismic slip. This observation agrees with that of Brune [1968], who found that the rate of slip in the Imperial Valley computed from seismic moments was less than the values obtained from geodetic measurements. The surface cracking preceding the Parkfield earthquake [Allen and Smith, 1966] which was not associated with microearthquake activity may have been stable sliding, which often precedes stickslip in the laboratory.

According to recent results of Byerlee and Brace [1968], stick-slip is only an intrinsic property of rock friction under certain conditions. They find that stick-slip at confining pressures below about $1 \mathrm{~kb}$ does not occur in all rock types they studied. In addition, stick-slip does not occur at any pressure in basic rocks such as gabbro and dunite which have even a very small amount of serpentine alteration.

These results present a rather interesting explanation of the die-off of seismic activity at about $15 \mathrm{~km}$ in California. This die-off seems too rapid to be due to simply an increase of ductility with temperature and pressure, and there is no evidence for the alternative that there is a low-viscosity layer in the crust. The experimental results suggest that the sudden drop-off seismic activity may be due to a change from granitic or sedimentary rock to altered basic rock at that depth. In northern California, a discontinuity of that nature between Franciscan sedimentary and basic intrusive rock and underlying rock of 6.8 velocity at about $12 \mathrm{~km}$ has been identified from refraction studies [Stewart, 1968]. 
Insofar as frictional properties are concerned, laboratory results suggested that the crust in California may be composed of three layers with the following properties: layer 1 , from the surface to a depth of 2 to $4 \mathrm{~km}$, in which stable sliding is the primary mode of slip, regardless of rock type, except when an earthquake propagates from below; layer 2, a generally granitic layer, extending to depths of about $12 \mathrm{~km}$ in the Parkfield area but which may vary in other regions, in which slip occurs by both stable sliding and stick-slip accompanied by earthquakes; and layer 3, underlying layer 2, composed of altered basic rock in which the primary mode of slip is stable sliding. We have no information as to what depth the fault may extend in layer 3 .

\section{Parkfield, California, Earthquakes of 1966}

The Parkfield-Cholame earthquake of June 27,1966 , and its aftershock sequence is one of the best studied seismic events. One of the most interesting, and unforeseen, observations was that after the main shock, slow slippage of the fault began to occur and is still continuing at the time of this writing, two years later. This behavior, which has been observed elsewhere on the San Andreas fault under different circumstances [Tocher, 1960b] has been known as fault creep. The term fault creep should in no way indicate a relation to the time-dependent rheology of metals and other materials but is used in this context merely to indicate slippage of the fault which is very slow in comparison with the elastic-wave velocity.

Fault creep may be a very important mode of crustal deformation, which has been largely overlooked in the past because of a lack of detailed instrumental observations. It represents one of the very few truly new aspects of faulting that has been uncovered in many years and may provide some important clues in unraveling the mechanism of seismic faulting.

Wallace and Roth [1967] and Smith and Wyss [1968] have independently reported their observations of fault creep following the Parkfield earthquake. Their chief observations were (1) that, the creep decayed off after the main shock with a logarithmic time law quite similar to the falloff of aftershock activity, and (2) that the fault creep as measured at the surface appeared to be composed of episodes of accel- erated creep that seem to be related in some way with felt aftershocks. The creep sequence, as well as the aftershock sequence, thus appears to have been generated by the main shock and the two seem to be interrelated in some way. We should now like to examine carefully all the pertinent observations of the Parkfield-Cholame earthquake sequence with the intent of developing a coherent model of the mechanics of the main shock, aftershocks, and fault creep.

Recent experimental studies of the frictional and fracture behavior of rock have greatly enhanced our understanding of how rock deforms under shallow crustal conditions. As we have made clear in the discussions above, these investigations have led to a number of hypotheses regarding the mechanism of earthquakes. Because of the very intensive studies that have been made of the Parkfield-Cholame earthquakes, this earthquake sequence presents a unique proving ground for the detailed testing of some of these ideas.

Mechanism of the Parkfield mainshock. As little as $\mathbf{1 0}$ hours after the mainshock, when slip by creep was taking place at a very rapid rate, Allen and Smith [1966] found that only a 4.5-cm displacement had taken place across the white line on highway 46. Observations elsewhere on the fault also indicated that the amount of slip produced during and shortly after the mainshock was small in comparison to that eventually produced by creep. Extrapolation back in time on the creep curves that were subsequently measured led to the conclusion that essentially no slip had occurred at the surface during the main shock [Smith and Wyss, 1968]. Even disregarding this extrapolation, the large-amplitude surface waves [Wu, 1968a] and accelerations [Aki, 1968b] both indicate, when compared with measured surface displacements, that slip during the main shock must have been much greater at depth than at the surface. This conclusion is also supported by the geodetic measurements of Hofmann [1967], which showed that almost $20-\mathrm{cm}$ displacement had taken place 6 to $8 \mathrm{~km}$ from the fault by July 1966 .

All the evidence thus points to a buried fault that underwent a considerable amount of slip at depth. Little or no slip occurred in the surface layer immediately during the earthquake, but creep was initiated which resulted in substantial 
slippage over the next few months. This suggests a causal relationship between the earthquake and the creep that followed it: the main shock did not propagate to the surface; consequently, the layer between the slipped region and the surface was highly stressed. The response of this layer was fault creep.

Before we discuss the rheology of the creep process we must first quantify the reconstruction of the main shock. Hofmann [1968] remeasured the California Department of Water Resources geodetic network in the Parkfield area and found that points $6 \mathrm{~km}$ from the fault had moved $2.5 \mathrm{~cm}$ between July 1966, immediately after the main shock, and May 1967. It was during this period that extensive creep occurred on the fault. At the Taylor ranch theodolite station, located near the center of Hofmann's network, $11.5 \mathrm{~cm}$ of displacement across the fault was recorded during the same time interval. These two measurements can be used in conjunction with elastic theory to estimate the depth of the creep zone. By using various models of fault slippage, these two measurements indicate that the depth of the creep zone (and accordingly the top of the zone faulted during the main shock) was between 2 and $4 \mathrm{~km}$ [Chinnery, 1961; Walsh, 1968].

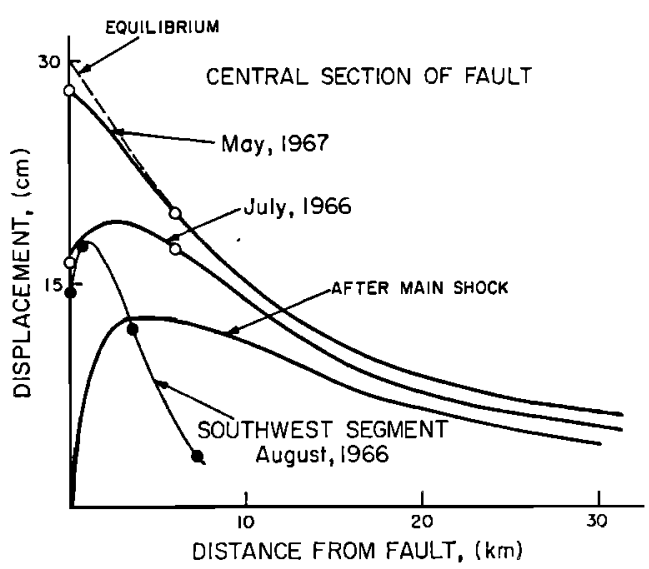

(a)
Eaton [1968] found that aftershock activity decreased very rapidly below $10 \mathrm{~km}$. No aftershocks were observed below $12 \mathrm{~km}$. It is very likely, therefore, that the bottom of the zone that slipped during the main shock was at about $10 \mathrm{~km}$. Taking as our model a dislocation $40 \mathrm{~km}$ long which slipped from 4 - to $10-\mathrm{km}$ depth, we find from the seismic moment of $1.9 \times 10^{23}$ dyne cm [Wyss and Brune, 1968] that a total slip of $30 \mathrm{~cm}$ occurred during the main shock. By early 1968, when creep activity had slackened to a very low rate, nearly all this displacement had been relased at the surface by creep. At that stage, the geodetic displacements are consistent with a surface fault of $10-\mathrm{km}$ depth which slipped $30 \mathrm{~cm}$.

In Figure 4 we illustrate our model. The displacements from the main shock were calculated from Chinnery's [1961] model. We assumed that the upper creep zone behaved like Walsh's [1968] model 1 , with $d / d_{*}=1$. In the left-hand diagram the theoretical displacement curves are fitted to the data. The fit to the creep data and to Hofmann's [1967, 1968] measurements is extremely good. According to this result, a zone from 4 to $10 \mathrm{~km}$ slipped $30 \mathrm{~cm}$ during the main shock, followed by creep in the surface layer. The upper $4 \mathrm{~km}$ had slipped

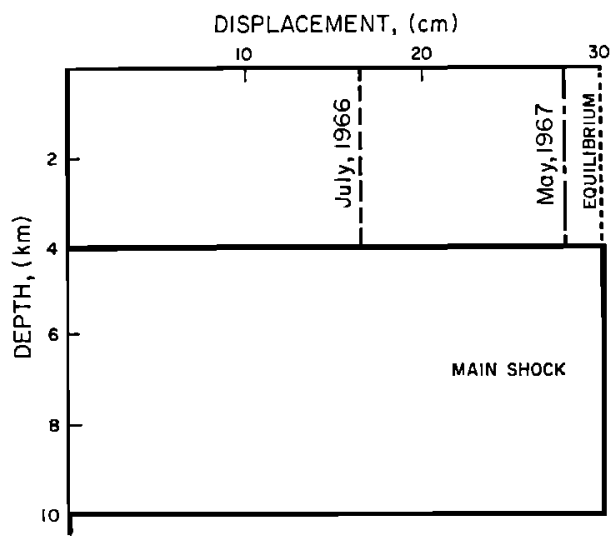

(b)

Fig. 4. Fault slip and displacements during and following the June 27, 1966, earthquake. The right-hand figure $(b)$ shows the inferred variation of slip with depth in the central section of the fault due to the main shock and at several later dates after creep had occurred in the surface layer. In the left-hand diagram (a), calculated displacements are shown for the central section of the fault immediately after the main shock and at two later dates where they are fitted to creep at Taylor Ranch and Hofmann's [1967, 1968] points (open circles). Displacements on a line across the southwest segment of the fault are also shown as solid circles [Wallace and Roth, 1967; Meade, 1966]. 
$16.5 \mathrm{~cm}$ by July 1966, and by May 1967, 28 $\mathrm{cm}$, nearly all the stored slip, had been released by creep. The creep layer probably does not correspond to a geologic layer. In the Cholame Valley the alluvium is estimated at several hundred meters [Dickenson, 1966] and seismic refractions studies by Eaton [1968] indicate discontinuities at $1.4-$ and $6-\mathrm{km}$ depth. It appears that the creep layer corresponds to the stable sliding layer expected from laboratory results. We shall test this suggestion in the next section.

$A k i$ [1968b] attempted to determine the mechanism of the main shock by synthesizing the accelerograph from a strong motion station located very close to the fault and just south of highway 46 . He concluded that the fault slipped $60 \mathrm{~cm}$ from a depth of $3 \mathrm{~km}$ to less than 100 meters from the surface. This accelerograph is only indicative of the displacement that took place on the extreme southern end of the faulted region, where the instrument was located. The U.S. Coast and Geodetic Survey reoccupied a geodetic network in this region in August 1966 [Meade, 1966]. The displacements observed from one of the traverses, which crossed the fault $4 \mathrm{~km}$ north of the accelerograph station, are shown in Figure 4. These data indicate that the fault may indeed have been quite shallow in that region, and again indicates, when combined with data from the quadrilateral QAB located across the fault by Wallace and Roth [1967], that displacements strongly increased with depth. Note, however, that a displacement greater than 20 to $30 \mathrm{~cm}$ is not consistent with these data.

This conflict is probably a result of the oversimplified model assumed by Aki. He used for simplicity a rupture velocity of $2.2 \mathrm{~km} / \mathrm{sec}$ within a uniform medium of $S$-wave velocity $3.5 \mathrm{~km} / \mathrm{sec}$. In the light of a detailed refraction study by the U.S. Geological Survey [Eaton, 1968] which showed that a low-velocity sediment ( $v_{p} \approx 3 \mathrm{~km} / \mathrm{sec}$ ) overlies the basement in the fault area to a depth of 1 to $2 \mathrm{~km}$, however, Aki noted that the rupture velocity may be supersonic in the near-surface layers. His calculations show that the inferred displacement may be reduced by as much as a factor of 2 if the rupture velocity approaches the shear-wave velocity. Consequently, because the effect of this layering has been neglected in his model considerable latitude must be placed on the interpretation of his results. We feel that his results may be construed as indicating only that displacements at depth, while not determined accurately, were significantly greater than observed at the surface. In any case, his results may be applied only to the southwest segment of the fault. The displacement on this part of the fault may have been quite different than the displacements on the central section. In the light of the uncertainties of his method, we do not feel that his results are in serious conflict with the present model of the main shock.

Although our synthesis of the mechanism of the main shock is certainly not uniquely determined, the strong self-consistency of the creep data, geodetic measurements, seismic moment, and aftershock distribution allow considerable confidence in the model. Perhaps more importantly, this model implies a generating mechanism for the creep and aftershocks that followed.

Creep and aftershocks. According to our interpretation of the experimental studies of friction, shallow and deep parts of the fault should slip primarily by stable sliding, whereas a central section from about 4 - to $12-\mathrm{km}$ depth is particularly prone to stick-slip and, consequently, to earthquakes. After the Parkfield earthquake, substantial creep occurred during the extensive aftershock sequence. Since both seismic and aseismic creep therefore occurred simultaneously in the same locality, excellent means are provided for directly comparing the two types of slip.

After the Parkfield earthquake, five smallscale geodetic stations were established across the main break [see Smith and Wyss, 1968]. The cumulative displacement to date of these five stations are plotted versus the logarithm of time in Figure 5. The ordinate for the data at each station is arranged so that the stations from north to south in the fault area are shown from top to bottom in the diagram. The time scale was arbitrarily fixed so that the origin time of the main shock is at $t=1$.

The clearest feature to be observed from Figure 5 is that for long periods of time the data fall on straight lines, i.e., the creep decays logarithmically in time. This pattern is most regular at Taylor Ranch, the station closest to the center of the fault break. The stepwise 


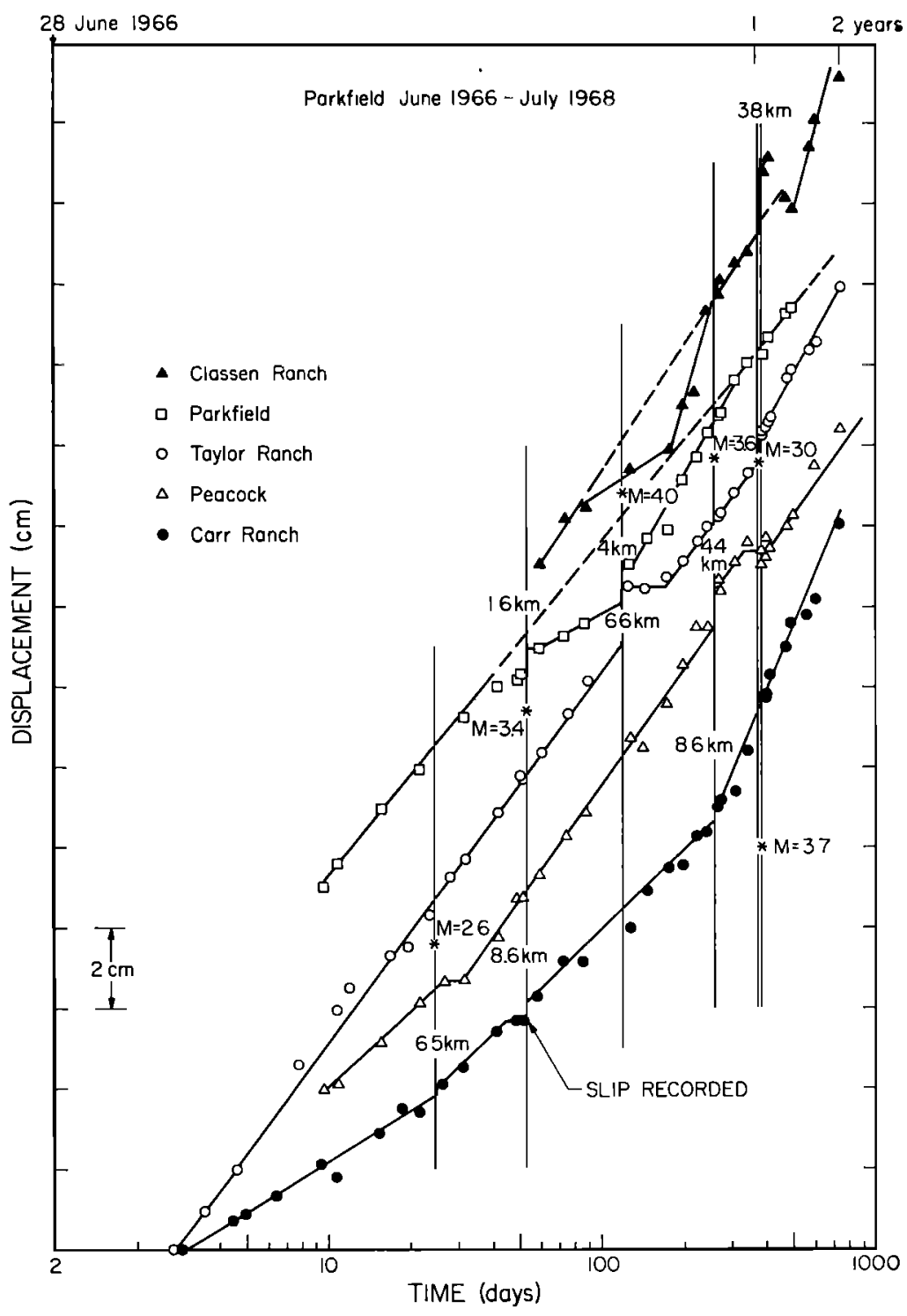

Fig. 5. Cumulative slip across the fault following the Parkfield earthquake measured with five small-scale geodetic networks and plotted semilogarithmically against time. The ordinate intercepts are arranged arbitrarily so that stations from north to south are from top to bottom in the figure. The mainshock was at $t=1$. The occurrence of several aftershocks which seem to have affected the creep are indicated by vertical lines with asterisks to indicate the relative position of the epicenters with respect to the theodolite stations and with the distances noted to associated measured slips.

deviations and the changes of slope of the lines are discussed in a later section.

The observation that creep following the Parkfield earthquake decayed approximately logarithmically in time, as did the aftershocks [Eaton, 1967], suggests that the two may be related. This possibility is strengthened by the observation of Smith and Wyss [1968] that the creep is not smooth but episodic and that such episodes often follow large aftershocks. This poses a number of interesting possibilities. One question that might be asked is: are the creep 
TABLE 1. Seismographic Stations in the Epicentral Region

\begin{tabular}{lllc}
\hline \multicolumn{1}{c}{ Name } & Latitude & Longitude & $\begin{array}{c}\text { Height, } \\
\text { meters }\end{array}$ \\
\hline Station 1 & $35^{\circ} 49.35^{\prime \prime}$ & $120^{\circ} 29.40^{\prime \prime}$ & 590 \\
Station 3 & $3^{\circ} 55.55^{\prime \prime}$ & $120^{\circ} 30.40^{\prime \prime}$ & 580 \\
Station 5 & $3^{\circ} 55.00^{\prime \prime}$ & $120^{\circ} 21.65^{\prime \prime}$ & 960 \\
Station 7 & $3^{\circ} 51.40^{\prime \prime}$ & $120^{\circ} 16.90^{\prime \prime}$ & 520 \\
Station 8 & $3^{\circ} 45.60^{\prime \prime}$ & $120^{\circ} 23.35^{\prime \prime}$ & 590 \\
Gold Hill & $3^{\circ} 49.9^{\prime \prime}$ & $120^{\circ} 21.2^{\prime \prime}$ & 370 \\
Carr Ranch* & $3^{\circ} 50.0^{\prime \prime}$ & $120^{\circ} 21.9^{\prime \prime}$ & 360 \\
\hline
\end{tabular}

* Location of creepmeter.

episodes really aseismic? It is possible, for example, that such creep episodes are accompanied by a swarm of microearthquakes, each of which contributes a small stepwise increment to the creep displacement.

To investigate the relationship between microearthquakes and fault creep, a five-station microearthquake array was operated in the Parkfield area from October 1, to November 15, 1967. This time interval was selected on the basis of past creep activity, which suggested that a creep episode might be expected by midOctober. The locations of these temporary stations, together with those of the U.S. Geological Survey Station Gold Hill, which was also used in the study, and the Carr Ranch creepmeter, are given in Table 1 and shown in Figure 7. The response of these stations, which are de- scribed by Brune and Allen [1967a], was such that any earthquake of magnitude 0 or greater that occurred within the array was perceptible. During the same period, the Invar wire creepmeter at Carr Ranch [Smith and Wyss, 1968] was equipped with a strip chart recorder so that a continuous creep record was obtained. The sensitivity of this device was about $10^{-4} \mathrm{~cm}$.

On October 21, three weeks after installation of the microearthquake array, a felt earthquake of magnitude 3.4 occurred in the Middle Mountain area. Eight days later creep began at Carr Ranch and continued until November 15, producing a total of about $0.2-\mathrm{cm}$ right-lateral fault slip. The time history of the creep episode measured at Carr Ranch and the local seismic activity are shown in Figure 6.

The seismic activity is shown as cumulative counts of earthquakes, which are divided into two groups: earthquakes that occurred from Middle Mountain south to highway 46 are shown in curve $A$, and earthquakes that occurred northwest of Middle Mountain and hence could not be located accurately with the array are shown in curve B. In Figure 7 we show the location of all shocks that were within the range of the array during the study. These data are also listed in Table 2.

A cursory examination of Figures 6 and 7 will convince the reader that there is no obvious direct relationship between local seismic activity and fault creep. In this sense, then, the creep episode is definitely aseismic in nature. It is

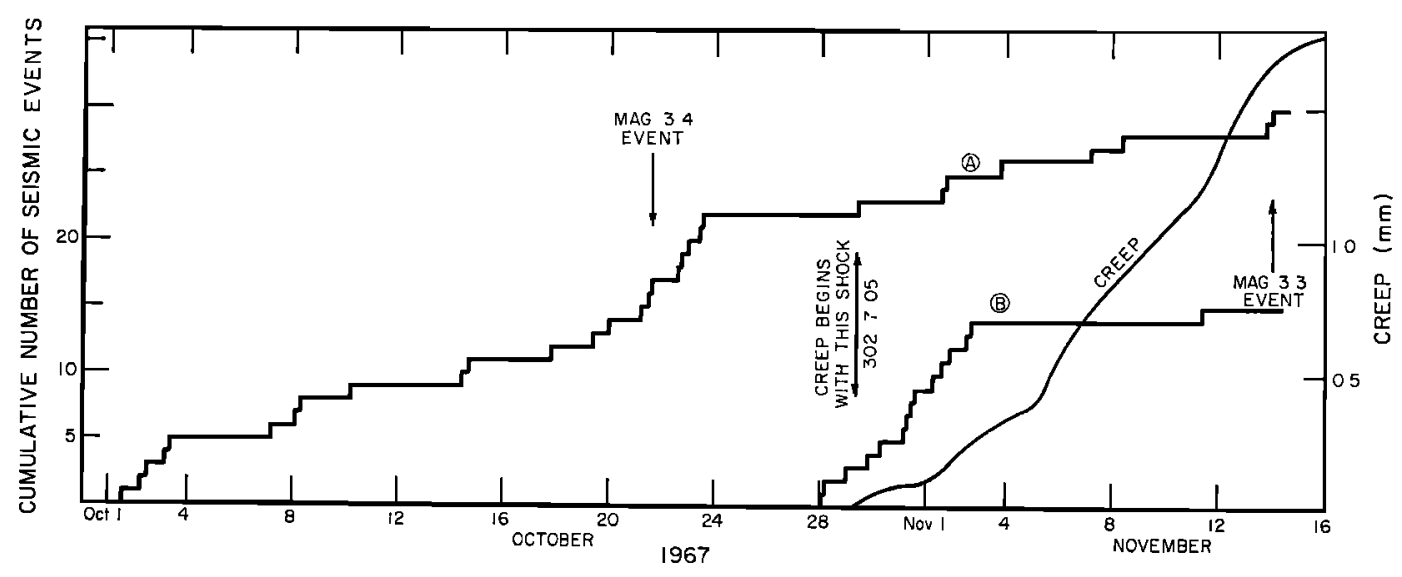

Fig. 6. Local seismic activity and creep, October and November 1967. Cumulative seismic activity from Middle Mountain south to highway 46 is shown by $(A)$ and that northwest of Middle Mountain by $(B)$. Creep measured at Carr Ranch. 
noticed, however, that there are some interesting variations in the seismicity of the area that may be described in passing. In the three weeks prior to the October 21 earthquake, small shocks occurred at a fairly regular rate and were located fairly uniformly over the $30-\mathrm{km}$ length of fault from Middle Mountain to highway 46 (solid circles in Figure 7).

This contrasts with the activity after October 21 (centered open circles), which was concentrated almost entirely in the Middle Mountain area and northward. The activity near Middle Mountain quieted down a few days after the October 21 shock, and no shocks occurred until the morning of October 28, when a swarm of activity began in the area north of Middle Mountain about 20 to $30 \mathrm{~km}$ northwest of Carr Ranch. A day later creep began at the same time as the occurrence of a small shock near Middle Mountain. The activity to the northwest lasted 6 days and ended as quickly as it had begun. Near the end of the creep episode, on November 14, another felt earthquake, of magnitude 3.3 , occurred in nearly the same place as the October 21 event.

Aside from the fact that major aftershocks often occur a short while before the beginning of creep episodes the above results indicate that there is little direct relationship of creep, either spatially or temporally, with local seismic activity. One might probe deeper and ask if they were at least correlated in sense. This seems to be the case. The composite fault plane solution (Figure 2) of the events located during this study are consistent with right-lateral motion on the fault.

The lack of direct correlation between creep and aftershocks becomes even more striking when we compare the creep displacements with the displacements inferred from aftershocks. We make this comparison in the following way.

The sum of the moments of all earthquakes that occur in a given time on a particular fault plane can be divided by the product of the area of this plane with the appropriate shear modulus. The result is the cumulative displacement per unit fault length corresponding to the seismic activity during the time considered [Brune, 1968]. Smith and Wyss [1968] pointed out that the displacement calculated from seismic radiation of the Parkfield aftershock sequence was much less than the geodetically observed creep

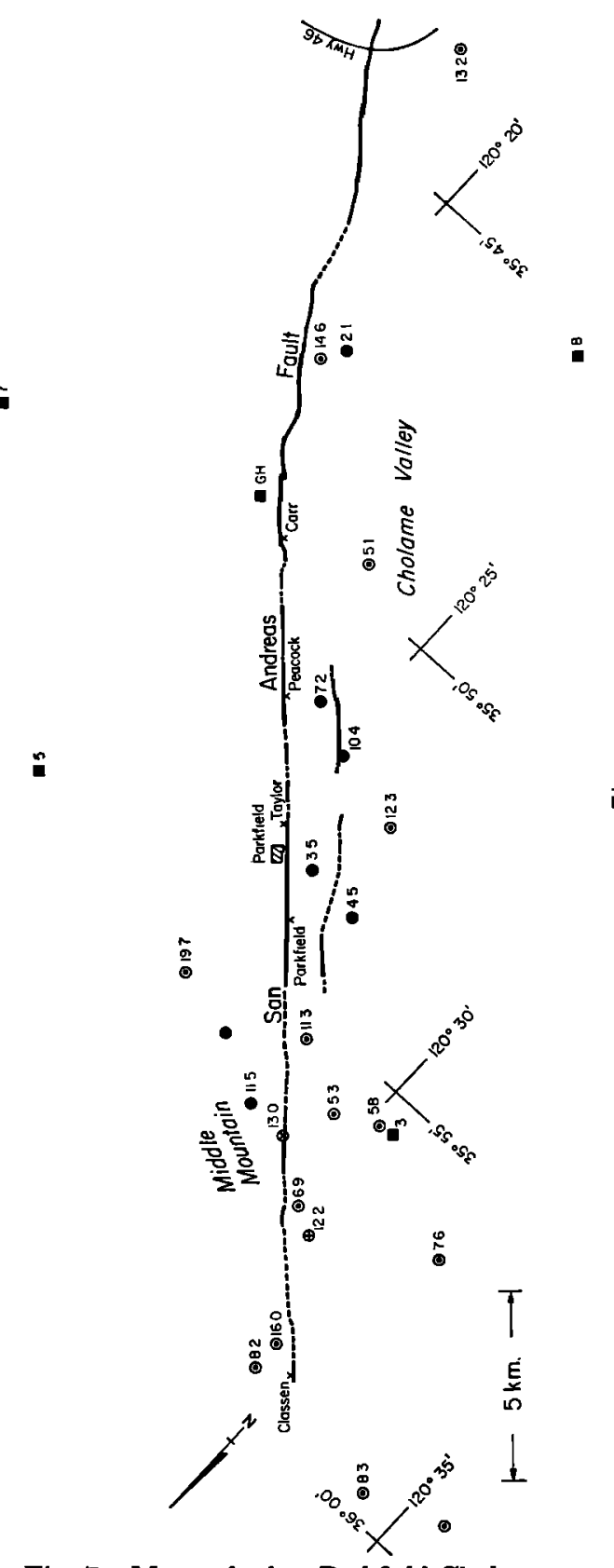

Fig. 7. Map of the Parkfield-Cholame area showing theodolite stations (crosses), portable seismic stations (solid squares), and microearthquakes located during the October-November 1967 study. Solid circles are epicenters of shocks that occurred from October 1 to October 21; centered open circles, October 21 to November 15 ; circle with $\mathrm{x}$ the $M=3.4$ October 21 event; crossed circle, the $M=3.3$ November 14 event. Numbers refer to corresponding depths. Fault trace is from Brown and Vedder [1967]. 
TABLE 2. Earthquake Locations in the Parkfield-Cholame, California, Area, October 1 to November 15,1967

\begin{tabular}{|c|c|c|c|c|c|c|c|}
\hline Date & h & $\begin{array}{l}\text { Time } \\
\mathrm{m}\end{array}$ & $\mathrm{s}$ & N. Latitude & W. Longitude & $\begin{array}{c}\text { Depth, } \\
\text { km }\end{array}$ & Magnitude \\
\hline Oct. 3 & 7 & 07 & 44.3 & $35^{\circ} 56.5^{\prime \prime}$ & $120^{\circ} 28.3^{\prime \prime}$ & 11.5 & \\
\hline Oct. 8 & 2 & 29 & 18.7 & $35^{\circ} 53.4^{\prime \prime}$ & $120^{\circ} 26.2^{\prime \prime}$ & 3.5 & \\
\hline Oct. 8 & 3 & 09 & 45.9 & $35^{\circ} 53.5^{\prime \prime}$ & $120^{\circ} 27.4^{\prime \prime}$ & 4.5 & \\
\hline Oct. 10 & 5 & 01 & 14.0 & $35^{\circ} 56.0^{\prime \prime}$ & $120^{\circ} 27.1^{\prime \prime}$ & $\ldots$ & \\
\hline Oct. 14 & 9 & 47 & 38.2 & $35^{\circ} 51.5^{\prime \prime}$ & $120^{\circ} 24.4^{\prime \prime}$ & 7.2 & \\
\hline Oct. 14 & 17 & 14 & 32.9 & $35^{\circ} 51.9^{\prime \prime}$ & $120^{\circ} 25.3^{\prime \prime}$ & 10.4 & \\
\hline Oct. 19 & 7 & 44 & 06.2 & $35^{\circ} 47.6^{\prime \prime}$ & $120^{\circ} 20.6^{\prime \prime}$ & 2.1 & \\
\hline Oct. 21 & 5 & 19 & 52.4 & $35^{\circ} 59.1^{\prime \prime}$ & $120^{\circ} 36.0^{\prime \prime}$ & $\cdots$ & 1.9 \\
\hline Oct. 21 & 11 & 32 & 38.1 & $35^{\circ} 59.2^{\prime \prime}$ & $120^{\circ} 31.5^{\prime \prime}$ & 8.2 & \\
\hline Oct. 21 & 12 & 05 & 23.6 & $35^{\circ} 58.6^{\prime \prime}$ & $120^{\circ} 31.2^{\prime \prime}$ & 13.2 & 3.4 \\
\hline Oct. 22 & 14 & 47 & 28.5 & $35^{\circ} 55.9^{\prime \prime}$ & $120^{\circ} 29.5^{\prime \prime}$ & 5.3 & \\
\hline Oct. 22 & 14 & 50 & 07.9 & $35^{\circ} 55.3^{\prime \prime}$ & $120^{\circ} 28.3^{\prime \prime}$ & 11.3 & \\
\hline Oct. 23 & 1 & 17 & 13.0 & $35^{\circ} 47.9^{\prime \prime}$ & $120^{\circ} 20.2^{\prime \prime}$ & 14.6 & \\
\hline Oct. 23 & 7 & 48 & 57.6 & $35^{\circ} 52.1^{\prime \prime}$ & $120^{\circ} 26.8^{\prime \prime}$ & 12.3 & \\
\hline Oct. 23 & 8 & 40 & 14.5 & $35^{\circ} 43.1^{\prime \prime}$ & $120^{\circ} 18.5^{\prime \prime}$ & 13.2 & \\
\hline Oct. 29 & 7 & 08 & 12.1 & $35^{\circ} 56.3^{\prime \prime}$ & $120^{\circ} 32.5^{\prime \prime}$ & 7.6 & \\
\hline Nov. 1 & 6 & 09 & 51.3 & $35^{\circ} 59.6^{\prime \prime}$ & $120^{\circ} 34.2^{\prime \prime}$ & 8.3 & \\
\hline Nov. 1 & 15 & 13 & 50.8 & $35^{\circ} 55.5^{\prime \prime}$ & $120^{\circ} 30.2^{\prime \prime}$ & 0.6 & \\
\hline Nov. 1 & 19 & 28 & 12.8 & $35^{\circ} 55.9^{\prime \prime}$ & $120^{\circ} 25.9^{\prime \prime}$ & 19.7 & \\
\hline Nov. 3 & 20 & 16 & 20.5 & $35^{\circ} 57.1^{\prime \prime}$ & $120^{\circ} 30.1^{\prime \prime}$ & 6.9 & \\
\hline Nov. 7 & 10 & 37 & 43.0 & $35^{\circ} 52.5^{\prime \prime}$ & $120^{\circ} 11.5^{\prime \prime}$ & $\ldots$ & \\
\hline Nov. 11 & 10 & 32 & 03.9 & $36^{\circ} 7.8^{\prime \prime}$ & $120^{\circ} 40.0^{\prime \prime}$ & $\ldots$ & \\
\hline Nov. 13 & 18 & 18 & 51.7 & $35^{\circ} 49.6^{\prime \prime}$ & $120^{\circ} 23.3^{\prime \prime}$ & 5.1 & \\
\hline Nov. 14 & 00 & 00 & 52.9 & $35^{\circ} 57.4^{\prime \prime}$ & $120^{\circ} 30.7^{\prime \prime}$ & 12.2 & 3.3 \\
\hline Nov. 14 & 2 & 44 & 29.8 & $35^{\circ} 58.8^{\prime \prime}$ & $120^{\circ} 31.5^{\prime \prime}$ & 16.0 & \\
\hline
\end{tabular}

displacement. They concluded that a substantial amount of creep, displacement not accompanied by seismic radiation, must have taken place. Creep and aftershocks have similar time histories. Next we inquire whether they are spatially correlated over the entire sequence.

To answer this question the displacement as inferred from seismic radiation was determined as a function of position along the fault and compared with the ground displacement measured at the surface. The most comprehensive study on hypocenters of the Parkfield sequence was made by Eaton [1968]. This study included only events that occurred between July and September 15, 1966; the corresponding magnitudes are not yet available. The list of shocks compiled by McEvilly et al. [1967] gives the magnitudes but it is less complete. Shocks up to January 12, 1967, are included in that list. For events after this date up to the present writing, the Pasadena Local Bulletin was used.

The hypocenters of all the earthquakes included in these three sources were projected onto the fault plane of the Parkfield 1966 break.
Then the moment of each shock was obtained. The fault plane was broken down into segments $2 \mathrm{~km}$ long and $10 \mathrm{~km}$-deep. The moment of all shocks located in each segment were summed and divided by the product of the segment area $\left(20 \mathrm{~km}^{2}\right)$ and shear modulus $\left(3 \times 10^{11}\right.$ dynes/ $\mathrm{cm}^{2}$ ). The average displacements caused by seismic events on fault segments obtained in this way are compared with the geodetically measured displacements in Figure 8.

The moments of the larger earthquakes were obtained by Wyss and Brune [1968]. The moments of smaller shocks were obtained by the moment-magnitude relation given by Parkfield earthquakes in that study. The displacement corresponding to the numerous shocks for which no magnitudes were available was estimated as follows: by using the frequencymagnitude relation of McEvilly et al. [1967] and the moment-magnitude relation of Wyss and Brune, the average moment of a Parkfield shock ( $2 \leq M \leq 3.5$ ) was determined. This value was then multiplied by the number of shocks with unknown magnitude per segment. 
This procedure is believed to be a fair estimate since (1) the magnitudes of all the large and important shocks are assigned and (2) the number of shocks per segment was between 20 and 100 , which justifies statistical treatment.

Earthquakes of $M_{L} \geq 3.5$ are expected to have fault dimensions larger than $2 \mathrm{~km}$. The fault dimensions of such shocks were estimated from the magnitude-fault length relation found by Wyss and Brune [1968]. Then the moments were distributed among a corresponding number of neighboring segments. A shock of magnitude 5, for example, is estimated to have fault dimensions of about $14 \mathrm{~km}$; therefore, its contribution to displacement was distributed among seven $2-\mathrm{km}$ segments centered around the epicenter.

In Figure 8 the displacements are plotted as a function of position along the fault. The fault race as mapped by Brown and Vedder [1967] is indicated as a solid line on the top of the figure. For reference, the locations of highway 46 and the town of Parkfield are indicated. The displacements obtained by small-scale geodetic measurements are relative to June 30,1966 ; on this date the displacement all along the fault was assumed to be zero [see Smith and Wyss, 1968]. The displacements as calculated from the seismic activity were obtained from the contributions of all shocks that occurred between June 27 and the present writing, except for the contribution of the main shock.

Comparing the displacements obtained in the two different ways, we observed two things. First, the displacement obtained from smallscale geodetic measurements are approximately an order of magnitude larger than the ones inferred from seismic activity. Second, regions of large surface displacements correspond to regions of low seismic activity, and conversely.

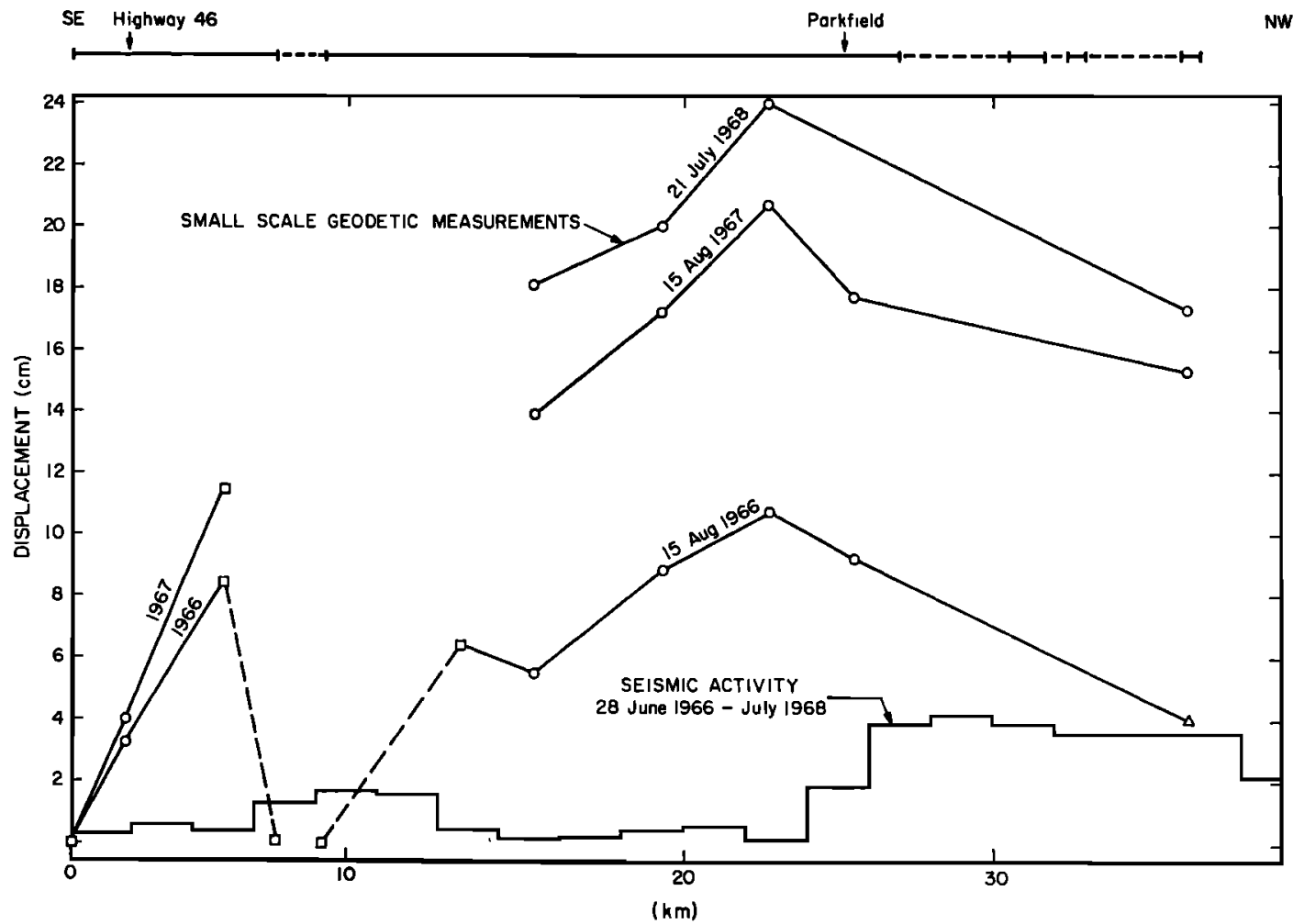

Fig. 8. Displacements across the San Andreas fault following the Parkfield earthquake as a function of position along the fault. Actual displacements measured with small-scale geodetic networks are compared with the displacements inferred from aftershock activity using the moment displacement relation. Note the anticorrelation. 
The seismic activity clusters around the ends of the main fault segment where the surface displacements decrease and go to zero.

According to a theory proposed by Scholz [1968b], aftershocks are due to time-dependent brittle fracture in regions of stress concentration produced by the main shock. If the region is isolated after the main shock and the aftershocks occur independently, the cumulative frequency of aftershock activity should decay logarithmically in time. This has been observed to be approximately the case at Parkfield [Eaton, 1967].

Spatially, aftershocks should be distributed most densely in zones of high stress concentration, i.e., primarily at the boundaries between slipped and unslipped regions. A concentration of aftershock activity at the ends or bottom of the slipped region is quite common. As has been pointed out above, the Parkfield aftershocks were concentrated in the Middle Mountain area at the north end of the slipped zone, and in an area $5 \mathrm{~km}$ north of highway 46. This latter region is at a point where the surface trace jumped across the Cholame Valley, leaving a 1-km gap in which no surface cracking was observed [Brown and Vedder, 1967]. The evidence that a high stress concentration existed in the region between the two fault segments lends credence to the idea that the main shock may have been a multiple event $[W u, 1968 b]$.

According to the model we have proposed for the main shock, however, the primary stress concentration was produced in the $4 \mathrm{~km}$ between the free surface and the slipped zone, i.e., the region in which creep occurred. The creep activity died off logarithmically in time after the main shock, similarly to the aftershocks, but the spatial distribution was converse; the maximum creep occurred in the central section of the fault and decreased rapidly toward the ends. Not only is the over-all slip produced by aftershocks negligible in comparison with the amount of fault creep, but the spatial distributions are uncorrelated.

It appears, then, that the regions bounding the faulted area responded in two different ways to the sudden stressing produced by the main shock. The upper $4 \mathrm{~km}$ above the fault responded by slow sliding that was not associated with substantial aftershock activity. The primary aftershock activity occurred at the ends of the fault. This is in agreement with what would be expected from experimental studies; major aftershock activity is confined to the stress concenrated regions in the stick-slip layer, i.e., below 2 to $4 \mathrm{~km}$ at the ends of the fault, whereas the shallow region above can only respond by stable sliding. Since microscopically stick-slip and stable sliding are both brittle fracture processes on an inhomogeneous surface, the analysis of Scholz [1968b] applies to both aftershock rates and creep rates. He treated the problem of an array of brittle elements in a random stress field, each of which is characterized by a time-deperdent strength and fails independently. His result for the case when the mean stress is held constant is that the cumulative number of elements which have fractured at time $t$ after application of the load is given by

$$
N=M C \log t+b
$$

where $M, C$, and $b$ depend on the state of stress, the materials, and the environment. By following the same sort of logic as Brune [1968] used in his calculation of rates of slip on faults from cumulative seismic moments, it is easy to see that equation 3 also describes the fault slip during an aftershock sequence. Each shock produces a small increment of slip. In the case of stable sliding, the actual fracturing is microscopic and a creep episode following the time law given in equation 3 is observed. From this viewpoint creep and aftershocks are independent but identical processes; the one leading to macroscopic fracture and the other resulting in smooth slip. They are both a response to stress concentrations produced by the main shock and are not interrelated.

Although creep and aftershocks were, over the long run, independent processes, we have not yet fully examined the possibility that individual aftershocks may have interacted with the creep sequence. Smith and Wyss [1968] reported an incident of a local aftershock that produced a slip followed by a period of accelerated creep. Their measurements, obtained by a strain meter stradling the surface break, revealed that most of the displacement occurred during periods of accelerated creep. A very regular pattern of creep episodes emerged during 1967 and 1968. The periods of accelerated creep last for about 5 days and always accumulate about $0.2 \mathrm{~cm}$ of relative displacement. The 
episodes are separated from one another by intervals of about 2 months during which very little displacement accumulated. Smith and Wyss attempted a correlation of periods of accelerated creep with aftershocks. They reached the conclusion that in 1967, when the aftershock activity had calmed down, all aftershocks reported as felt at the locality of measurement were followed by accelerated creep and, further, that no accelerated creep occurred without the occurrence of a felt shock.

The displacement measured by the Invar wire strain meter from its installation to the present is plotted in Figure 9. Occurrences of earthquakes that possibly could be correlated with creep periods are marked. The marked shocks before December 1, 1967, were all reported as felt at the locality of measurement. For the time after December 1, no record of felt reports is available. Therefore, all the shocks with $M \geq 3$ that occurred in the Cholame Valley and Middle Mountain regions are plotted. This illustrates that no direct correlation exist for all earthquakes, since there are several examples of aftershocks not followed by creep and the converse. Nothing new can be added to the apparent correlation with felt shocks. Although we have demonstrated that the over-all slip produced by aftershocks was insufficient to produce the creep, we should like to examine whether that may indeed not be the case for individual episodes. In particular we would like to check the hypothesis that creep episodes that follow aftershocks are the response of the surface layer to displacements produced at depth by these shocks.

In Table 3 we list the aftershocks that shortly preceded creep episodes. Except the October 21, 1967, event, which we described above, the relations between these shocks and their associated creep episodes have been described by Smith and Wyss [1968] or by Wyss and Brune [1968]. Our present intent is to check if these shocks are sufficiently large to have ruptured at depth an area long enough to extend from the hypocenter to underneath the site of displacement measurement and to have produced there a slip of an order that could account for the observed creep episode. We use the relation

$$
M_{0}=\mu A\langle U\rangle
$$

where $M_{0}$ is the seismic moment, $\mu$ is the rigidity, $A$ is the fault area, and $\langle U\rangle$ is the mean slip. We assume that the fault slipped beneath the $4-\mathrm{km}$ creep layer. A minimum fault width is therefore given by the hypocentral depth minus $4 \mathrm{~km}$, whereas a minimum fault length is generally taken as the distance from the epicenter to the Carr Ranch creepmeter. The product of these two values gives a minimum
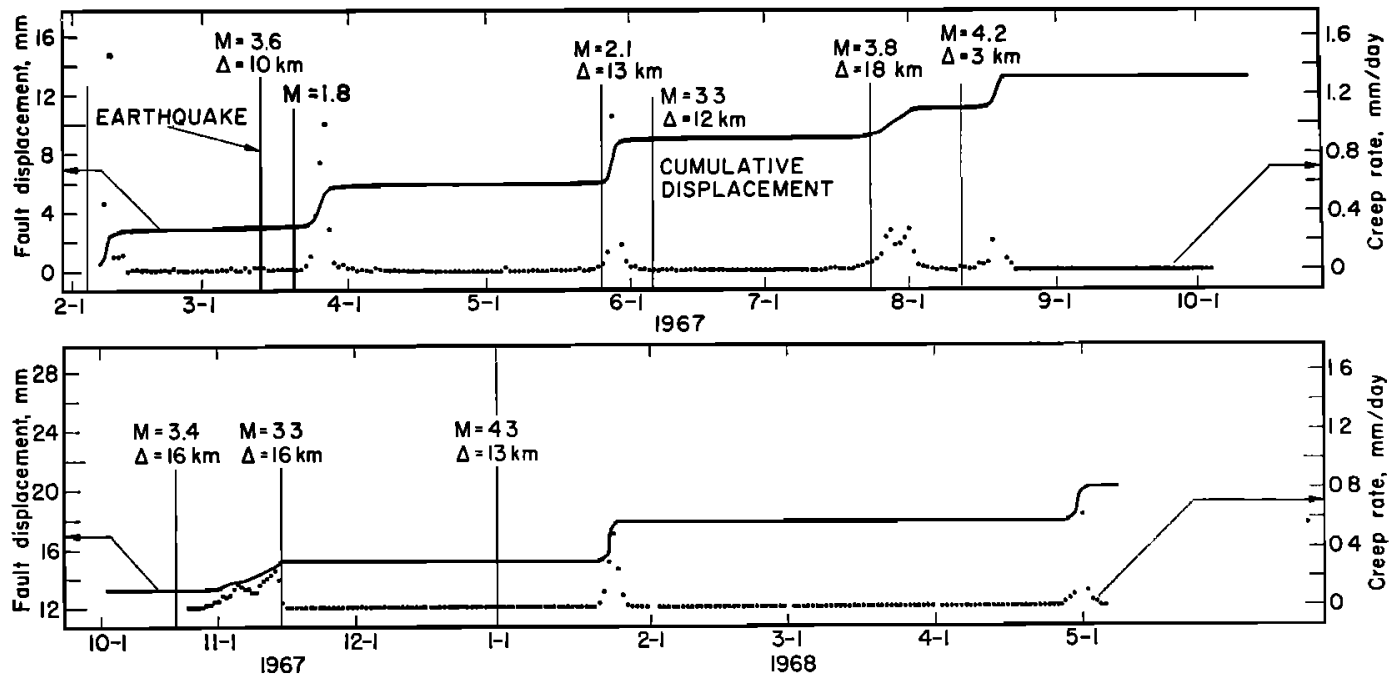

Fig. 9. Creep rate and cumulative creep measured with the Invar wire creepmeter at Carr Ranch during 1967 and 1968. Earthquakes and their distance from the creepmeter and magnitude are noted. Note the episodic nature of creep. 
TABLE 3. Comparison of Slip Observed in Creep Episodes to that Calculated from Preceding Earthquakes Assumed $\mu=3 \times 10^{11}$; area $A=$ length $\times$ (depth $-4 \mathrm{~km}$ ).

\begin{tabular}{|c|c|c|c|c|c|c|c|c|c|}
\hline \multirow[b]{2}{*}{ Date } & \multirow[b]{2}{*}{ h } & \multirow{2}{*}{$\begin{array}{l}\text { Time } \\
\text { m }\end{array}$} & \multirow[b]{2}{*}{ B } & \multirow{2}{*}{$\begin{array}{c}\text { Depth, } \\
\text { km }\end{array}$} & \multirow{2}{*}{$\begin{array}{c}\text { Length, } \\
\text { km }\end{array}$} & \multirow{2}{*}{$\underset{\text { dyne cm }}{M_{0}, *}$} & \multirow[b]{2}{*}{ Magn. } & \multicolumn{2}{|c|}{ Slip, cm } \\
\hline & & & & & & & & Observ. & Calc. \\
\hline Oct. 21, 1967 & 12 & 05 & 23.6 & 13.2 & 20 & $0.4 \times 10^{22}$ & 3.4 & 0.2 & 0.007 \\
\hline July 24, 1967 & 02 & 08 & 53.7 & 7 & 18 & $1.1 \times 10^{22}$ & 3.8 & 0.2 & 0.07 \\
\hline Oct. 27,1966 & 12 & 06 & 03.9 & 10.7 & 8 & $3.0 \times 10^{20}$ & 4.0 & 1.0 & 0.19 \\
\hline July 2, 1966 & 12 & 08 & 33.5 & 6.3 & 8 & $.73 \times 10^{20}$ & 3.6 & 1.0 & 0.13 \\
\hline Aug. 19, 1966 & 22 & 51 & 20.1 & 6.6 & 2.2 & $.35 \times 10^{22}$ & 3.4 & 0.7 & 0.24 \\
\hline March 13, 1967 & 21 & 59 & 47.4 & 10 & 10 & $.70 \times 10^{22}$ & 3.6 & 0.3 & 0.039 \\
\hline May 26, 1967 & 07 & 26 & $\ldots$ & $1 \times 10^{-2} \dagger$ & 13 & $1.0 \times 10^{20}$ & 2.1 & 0.2 & $\cdots$ \\
\hline
\end{tabular}

* $M_{0}$ from Wyss and Brune [1968].

$\dagger$ Fault width calculated from observed slip.

fault area required by the hypothesis we are checking. Using values of $M_{0}$ from $W y$ ss and Brune [1968], we can calculate the slip over such a hypothetical area during these shocks and compare it with that observed during the following creep episode. The computed values, listed in Table 3, are consistent in that the amount of slip calculated for each shock is at least an order of magnitude smaller than the amount observed during the subsequent creep episode. In addition, a few notable instances are documented in which an aftershock produced no slip at the stations in its vicinity but did appear to produce displacement at stations at considerable distance from the epicenter. These shocks are shown in Figure 5 with asterisks indicating their relative position to the creep stations and the distances to the points at which anomalous slip was observed. These instances are the shock at $t=25$ (July 20,1966), which produced a small slip at Carr, that on $t=53$ (August 19, 1966), which produced slip at Parkfield, and that on $t=122$ (October 27, 1966), which produced some slip at Parkfield and Taylor. We conclude that the hypothesis does not hold and the observed creep displacements cannot be entirely the result of the preceding earthquake such as by the time-delayed response to slip on a buried fault plane. If the correlation between aftershocks and creep episodes is indeed real, an alternative possibility is a dynamic triggering mechanism; i.e., the shaking from the aftershock triggered in some manner the release of strain stored in the creep layer. This alternative is quite a real possibil- ity: the April 9, 1968, Borrego Mountain earthquake seems to have caused displacements on three separate faults up to $70 \mathrm{~km}$ from the epicenter [Allen et al., 1968]. It is perhaps significant that all the earthquakes that have been associated with creep episodes at Parkfield were felt at the locality of creep measurements, indicating that they exceeded a threshold in shaking intensity.

We have not yet explained the episodic nature of the surface creep. A clue is found when the displacements shown in Figure 9 are plotted in semi-logarithmic coordinates, as shown in Figure 10. A most interesting observation emerges. The beginning and the end points of each creep episode describe straight parallel lines. The parallelism suggests that each creep episode releases a critical amount of strain, and the straightness suggests that such strain is being accumulated and released at a logarithmic rate in time. This may be understood in the following way. According to equation 3 creep should occur at a logarithmic rate with a decay constant $M C . M$ is, however, stress-dependent. Experimental results Scholz [1968c] show that $M$ is usually a power function of stress with an exponent generally greater than one. Since the stress concentration in the creep zone following the Parkfield earthquake must have been greatest at the top of the slipped region, decreasing toward the surface, the decay constant, and hence the rate of creep, must also have decayed toward the surface. Therefore, slip near the bottom of the creep zone was always 'leading' that near the surface, and the surface materials 
had a threshold strength such that slip could not occur until a critical amount of strain had accumulated from creep at depth.

The starting and stopping of the accelerated creep episodes occur with an amazing regularity. In all cases the actual beginning and end points are within $0.05 \mathrm{~cm}$ of the straight lines. This regularity makes it possible to predict the occurrence of creep episodes with a high confidence. On this basis, the episode of August 22, 1968, was predicted to occur on August 15. This was the first successful prediction of motion on the San Andreas fault.

The creep displacements obtained in 1966, starting 10 days after the Parkfield earthquake, are shown in Figure 11. These displacements were recorded by a quartz strain meter [see Smith and Wyss, 1968] at the same site as discussed above. These data also support the above ideas. The regularities are somewhat less pronounced, however. The explanation may be sought in the frequent occurrence of aftershocks which continuously altered the local stress pattern during the 3 months following the main earthquake.

The changes of slope of the limiting lines need explanation. Comparisons with the small- scale geodetic measurements at the same locality indicate that after January 1967 (200 days after the Parkfield 1966 earthquake) the strain meter was no longer straddling the entire fault zone. For this reason the slope in Figure 10 is smaller than the prevailing slope in Figure 11. The changes in slope during the earlier period of measurements, however, are also reflected in the geodetic measurements. Several changes in the slope of displacement versus log $t$ plots can be seen in Figure 5, most notably at Carr Ranch. These changes cannot be explained by the occurrence of local shocks. This phenomenon represents a change of the decay constant, which according to theory, can only be due to a change in stress. This may be a result of an original variation of stress concentration along the length of the fault following the main shock, resulting in some sections of the fault 'leading' others in creep. For almost a year after the main shock surface displacement was accumulating faster at the center of the fault, Taylor Ranch, then toward the southern end, at Carr Ranch (see Figure 5). The strain between these two points due to the difference in creep rates reached $10^{-3}$ in about 130 days. After this time the rate of creep at Carr Ranch increased in

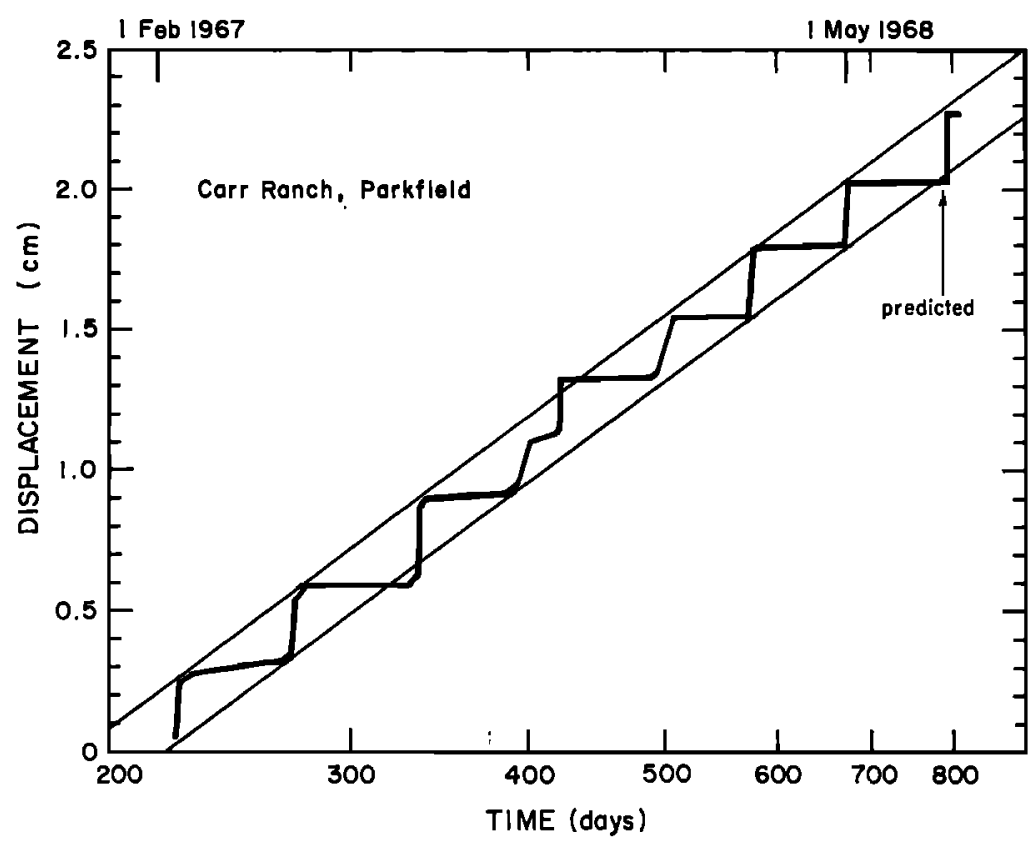

Fig. 10. The cumulative creep from Figure 9 is plotted semilogarithmically. The beginning and end of creep episodes define two straight parallel lines. The mainshock was at day 1. 


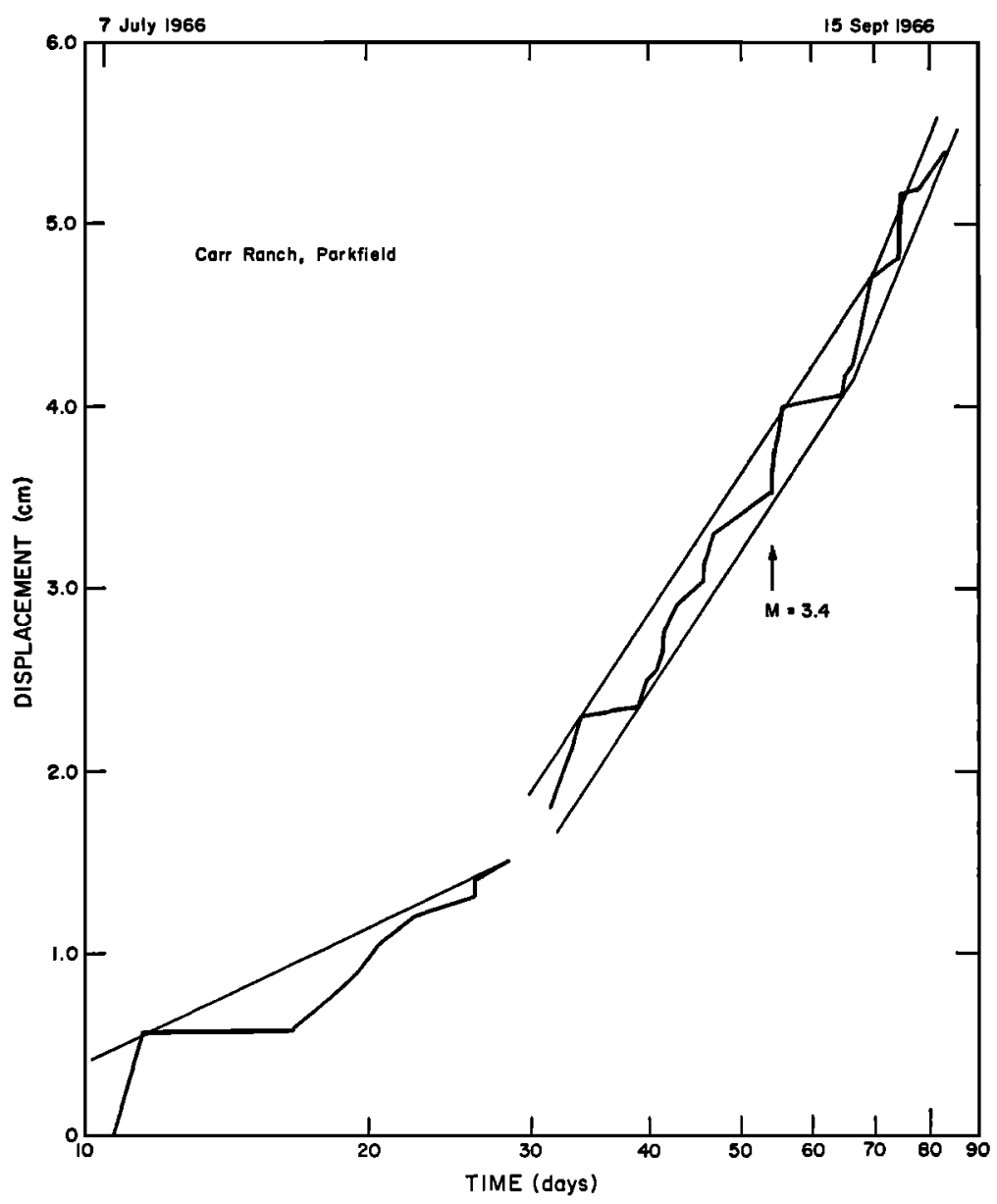

Fig. 11. Same as Figure 10 at an earlier time when a quartz tube straddled the fault.

such a way as to catch up with the more northerly points. It is very likely that neighboring portions of the fault influence one another in such a way, although an explanation for the suddenness of such transitions is lacking.

\section{Conclusions}

We have shown that the central section of the San Andreas fault is an extremely weak zone and that its strength is approximately that required for stick-slip friction. As an example of faulting on the San Andreas, we deduced that the 1966 Parkfield earthquake was a buried dislocation which underwent a slip of $30 \mathrm{~cm}$. As a result, stress concentrations about the fault produced creep and aftershocks sequences, which are two independent facets of time-dependent frictional sliding. These two phenomena are compatible with laboratory friction experiments and with a creep rupture theory of aftershocks. One feature of creep not observed in the laboratory is its episodic nature. However, after creep rates had decreased to a moderate level, the repetitive nature of creep episodes allowed the occurrence of episodes to be predicted with an accuracy of about 1 week on the basis of empirical induction.

If these conclusions are valid, we should be able to generalize them to other parts of the San Andreas system. Fault creep has been studied in detail in two other such areas: at the Hollister region of the San Andreas in northern California [Tocher, 1960b], and at Borrego Mountain on the San Jacinto fault system in southern California [Allen et al., 1968]. In these localities, creep is quite different 
than that at Parkfield. Creep at Hollister also occurs in sequences that decay logarithmically, but in contrast to Parkfield these sequences do not follow major earthquakes. At Borrego Mountain, on the other hand, sensitive creep measurements initiated only a few hours after the magnitude 6.5 earthquake of April 9, 1968, failed to reveal any creep following that earthquake. How can we explain these features from our Parkfield analysis?

In Figure 12 we show three cases of our general model of the crust with three layers of differing frictional properties. Figure $12 a$ illustrates the situation as it is inferred to have existed at Parkfield. The heavy depth versus stress curve represents the frictional strength; the shaded area, the tectonic stress. Since the Parkfield earthquake did not propagate to the surface, the tectonic stress must have reached the frictional strength only at depth and must have been much less than frictional strength near the surface. The regions of stress concentration following the earthquake were at the ends, in the stick-slip zone, where aftershocks occurred, and at the top, where creep occurred. The bottom is no problem; the region below 12 $\mathrm{km}$ may have been sliding smoothly prior to the earthquake and, rather have than been loaded by it, was strain-relieved.

The situation at Hollister is very likely the converse of that at Parkfield. The tectonic stress there, illustrated in Figure 12c, likely increases less sharply with depth than the frictional strength. In that case, faulting will propagate downward from the surface; i.e., creep will first occur in the stable sliding layer. Such creep will produce stress concentrations below; consequently, the creep episode may be followed by aftershocks if it extends to the stick-slip zone. This is in fact what is observed at Hollister: earthquakes follow creep episodes [Niazi, 1964; Breiner and Kovach, 1968].

The Borrego mountain earthquake is more of a 'normal' earthquake in the classical sense that rupture occurred from the surface down to a considerable depth. Displacements measured in the field shortly after the main shock are quite in accord with those expected from a shock of that size. Therefore, stress was not augmented in the stable sliding zone but only at the ends of the fault where aftershock activity was strongly concentrated (C. R. Allen, personal communication, 1968). Creep was not produced in this case, illustrated in Figure $12 b$.

In conclusion, we should like to point out some puzzling features not as yet understood. For one thing, we have been able to explain the general spatial and temporal patterns of fault creep, but as yet its short-term episodic nature, as observed at Parkfield, has not been observed in the laboratory. This will be an interesting topic of future research. More puzzling yet is the initiation of the logarithmically decaying creep episodes at Hollister. According to our analysis, based on the theory presented by Scholz [1968b], such a creep sequence is produced by a sudden increase, much faster than the rate of tectonic loading, of the stress on the fault. It is hard to explain how such a change in the stress field could occur without a release of seismic energy. The magnetic transients that have been observed to precede the creep epi-

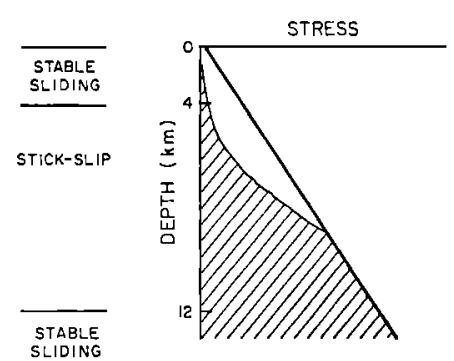

(a)

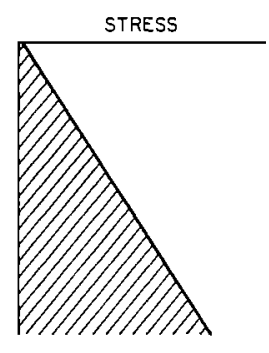

(b)

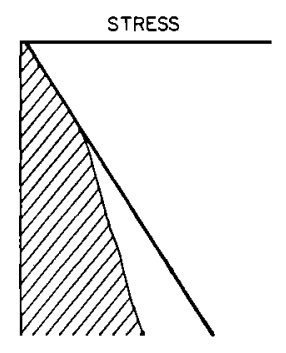

(c)

Fig. 12. A schematic representation of the stress and strength distribution with depth in three different situations. (a) Tectonic stress (shaded region) reaches only the frictional strength (heavy line) at depth; the situation at Parkfield. (b) The situation such as at Borrego Mountain, where the strength is attained all over the fault surface. (c) The situation such as at Hollister where strength is reached only in the upper stable sliding region. 
sodes at Hollister [Breiner and Kovach, 1968] may be symptomatic of such a change.

The results of this study should not be construed as applicable only to the San Andreas fault. Very likely faulting on other shallow faults is quite similar. For example, the Tashkent earthquake of April 26, 1966, was a buried shock followed by creep, and in this sense it was very similar to the Parkfield earthquakes [Ulomov and Mavashev, 1967].

Acknowledgments. We would like to thank Jerry P. Eaton of the US. Geological Survey for supplying us with data from the Gold Hill seismographic station and for allowing us the use of his data on aftershock locations prior to publication. J. Brune, J. Byerlee, W. F. Brace, and K. Aki also are thanked for the use of their manuscripts prior to publication. We also thank Jack Oliver, Clarence Allen, Lynn Sykes, and Peter Molnar for reviewing the manuscript.

This research was supported by the National Science Foundation under grant GA 1087 (Earthquake Mechanisms).

\section{REFERENCES}

Aki, K., Source mechanism of the Parkfield earthquake (abstract), Proc. Conf. on Geologic Problems of San Andreas Fault System, Stanford Univ. Publ. Geol. Sci., 11, 83, 1968a.

Aki, K., Seismic displacements near a fault, $J$. Geophys. Res., 73(16), 5359-5377, $1968 b$.

Allen, C. R., A. Granz, J. N. Brune, M. M. Clark, R. Sharp, T. G. Theodore, E. W. Wolfe, and M. Wyss, The Borrego Mountain, California, earthquake of 9 April 1968, a preliminary report, Bull. Seismol. Soc. Am., 58, 1183-1186, 1968.

Allen, C. R., P. St. Amand, C. F. Richter, and J. M. Nordquist, Relationship between seismicity and geologic structure in the southern California region, Bull. Seismol. Soc. Am., 55, 753-797, 1965.

Allen, C. R., and S. W. Smith, Parkfield earthquakes of June 27-29, Monterey and San Luis Obispo counties, California. Pre-earthquake and post-earthquake surficial displacements. Bull. Seismol. Soc. Am., 56, 966-967, 1966.

Allen, C. R., The tectonic environments of seismically active and inactive areas along the San Andreas fault system, Proc. Conf. on Geologic Problems of San Andreas Fault System, Stanford Univ. Publ. Geol. Sci., 11, 70-82, 1968.

Brace, W. F., and J. D. Byerlee, Stick-slip as a mechanism for earthquakes, Science, 158,990 992, 1966.

Breiner, Sheldon, and Robert L. Kovach, Search for piezomagnetic effects on the San Andreas fault, Proc. Conf. on Geologic Problems of San Andreas Fault System, Stanford Univ. Publ. Geol. Sci., 11, 111-117, 1968.

Brown, Robert D., and J. D. Vedder, Surface tectonic fractures along the San Andreas Fault, The Parlfield-Cholame, California Earthquakes of June-August 1966, US. Geol. Surv. Profess. Paper, 579, 2-22, 1967.

Brune, James, N., Seismic moment, seismicity, and rates of slip along major fault zones, $J$. Geophys. Res., 73(2), 777-784, 1968.

Brune, James N., and Clarence R. Allen, A microearthquake survey of the San Andreas fault system in southern California, Bull. Seismol. Soc. Am., 57, 277-296, 1967a.

Brune, James N., and Clarence R. Allen, A low stress-drop, low-magnitude earthquake with surface faulting. The Imperial, California, earthquake of March 4, 1966, Bull. Seismol. Soc. Am., 57, 501-514, $1967 b$.

Brune, James N., R. Roy, and T. Henyey, Heat flow and stress along the San Andreas fault near Hollister, California, preprint, 1968.

Byerlee, J. D., Frictional characteristics of granite under high confining pressure, J. Geophys. Res., 72(14), 3639-3648, 1967a.

Byerlee, J. D., Theory of friction based on brittle fracture, J. Appl. Phys., 38, 2928-2934, $1967 b$.

Byerlee, J. D., and W. F. Brace, Stick-slip, stable sliding, and earthquakes, $J$. Geophys. Res., $73(18), 6031-6039,1968$.

Chinnery, M. A., The deformation of the ground around surface faults, Bull. Seismol. Soc. Am., 51, 355-372, 1961.

Dickenson, William R., Structural relationship of San Andreas fault system, Cholame Valley, and Castel Mountain range, California, Bull. Geol. Soc. Am., 77, 707-721, 1966.

Eaton, Jerry P., Instrumental seismic studies, in The Parkfield-Cholame California Earthquakes of June-August, 1966, U.S. Geol. Survey, Profess. Paper, 679, 57-65, 1967.

Eaton, Jerry P., Spacial distributions of aftershocks of the June 27, 1966, Parkfield-Cholame earthquake in the San Andreas fault zone (abstract), Proc. Conf. on Geologic Problems of San Andreas Fault System, Stanford Univ. Publ. Geol. Sci., 11, 84, 1968.

Handin, J., and D. W. Stearns, Sliding friction of rock (abstract), Trans. Am. Geophys. Union, $45,103,1964$.

Hofmann, Renner B., Earthquake engineering programs progress report, Calif. Dept. of Water Resources Bull. 116-4, 1967.

Hofmann, Renner B., Geodometer fault movement investigations in Calif., Calif. Dept. of Water Resources Bull. 116-6, 1968.

Jaeger, J. C., The frictional properties of joints in rocks, Geofis. Pura Appl., 43, 138-158, 1959.

King, Chi-Yu, and Leon Knopoff, Stress drop in earthquakes, Bull. Seismol. Soc. Am., 68, 249257, 1968.

Leeman, E. R., The measurement of stress in rock, 3, J. South African Inst. Mining Met., 254-284, 1964.

McEvilly, T. V., W. H. Bakun, and K. B. Casaday, The Parkfield, California, earthquakes of 
1966, Bull. Seismol. Soc. Am., 57, 1221-1244, 1967.

Meade, B. K., Report on results of triangulation for earth movement study, vicinity of Cholame, Calif., Mem., ESSA, Coast Geodetic Surv., 3 pp. Washington Science Center, Rockville, Md., 1966.

Niazi, Mansour, Seismicity of northern California and western Nevada, Bull. Seismol. Soc. Am., 54, 845-850, 1964.

Orowan, E., Mechanism of seismic faulting, in Rock Deformation, Geol. Soc. Am. Mem., 79, 323-347, 1960.

Scholz, C. H., Microfracturing and the inelastic deformation of rock, J. Geophys. Res., 73(4), 1417-1432, $1968 a$.

Scholz, C. H., Microfractures, aftershocks, and seismicity, Bull. Seismol. Soc. Am., 58, 1117$1130,1968 b$.

Scholz, C. H., Mechanism of creep in brittle rock, J. Geophys. Res., 78(10), 3295-3302, 1968 c.

Smith, Stewart W., and Max Wyss, Displacement on the San Andreas fault initiated by the 1966 Parkfield earthquake, Bull. Seismol. Soc. Am., 58, 1955-1974, 1968.

Stewart, S. W., Preliminary comparison of seismic travel times and inferred crustal structure adjacent to the San Andreas fault in the Diablo and Gabilan ranges of Central California, Proc. Conf. on Geologic Problems of San Andreas Fault System, Stanford Univ. Publ. Geol. Sci., 11, 218-231, 1968.

Tocher, D., Movement on faults, Proc. Ind World Conf. Earthquake Eng., 1, 551-564, 1960a.
Tocher, D., Creep rate and related measurements at Vineyard, California, Bull. Seismol. Soc. Am., 50, 396-404, $1960 b$.

Tsuboi, C., Earthquake energy, earthquake volume, aftershock area, and strength of the earth's crust, J. Phys. Earth, 4, 63-66, 1956.

Ulomov, V. I., and B. Z. Mavashev, Forerunner of a strong tectonic earthquake (abstract), Dokl. Akad. Nauk Moscow SSSR, 176(2), 319-321, 1967.

Vasil'yev, Yu. F., Model of a seismic fault, Izv. Acad. Sci. USSR, Earth Phys., no. 3, 11, (AGU English transl., no. 3, 148), 1968.

Wallace, R. E., and E. F. Roth, Rates and patterns of progressive deformation, The ParkfieldCholame, California Earthquakes June-August 1966, U. S. Geol. Survey Profess. Paper, 579, 23-40, 1967.

Walsh, J. B., Mechanics of strike-slip faulting with friction, J. Geophys. Res., 73(2), 761-776, 1968.

Wu, Francis T., Parkfield earthquake of June 27, 1966: Magnitude and source mechanism, Bull. Seismol. Soc. Am., 58, 689-711, 1968a.

Wu, Francis T., A question put to J. Filson, Proc. Conf. on Geologic Problems of San Andreas fault system, Stanford Univ. Publ. Sci., 11, 86, $1968 b$.

Wyss, Max, and James N. Brune, Seismic moment, stress and source dimensions for earthquakes in the California Nevada region, $J$. Geophys. Res., 7S(14), 4681-4698, 1968.

(Received November 7, 1968; revised December 27, 1968.) 